ISSN 1112-9867

Available online at $\quad$ http://www.jfas.info

\title{
LEAN PRODUCTION AND BUSINESS PERFORMANCE: INFLUENCES OF LEADERSHIP STYLES
}

\author{
A. R. Zarinah*, A. M. Nur Farhana, and A. H. Nadiah \\ Faculty of Accountancy, Universiti Teknologi MARA, 40450 Shah Alam, Malaysia
}

Published online: 17 October 2017

\begin{abstract}
Current global economy creates intense competitive environment among businesses to ensure their survival in the present challenging market. Strategic view and formulation is crucial to enhance efficiencies and effectiveness of the businesses performance. Prior research however found lack of leader's intervention can lead to failures in lean production implementation. Hence, this study aims to examine the influence of leadership style in the implementation of lean production. Data were gathered from randomly selected Malaysian manufacturing firms. Findings reveal a positive relationship between lean production and business performance. Specifically, democratic leadership style was identified to moderate the relationship between lean production and business performance.
\end{abstract}

Keywords: lean production; business performance; leadership styles; autocratic; democratic; laissez-faire.

Author Correspondence, e-mail: zarinah371@salam.uitm.edu.my

doi: http://dx.doi.org/10.4314/jfas.v9i5s.71 


\section{INTRODUCTION}

The current global economy creates an intensely competitive environment among businesses and survival is one important struggle among all businesses in any type of industries [34]. In order to improve the efficiencies and effectiveness of their performance, good strategic view and formulation are needed. Businesses are always in the position of having less systematic production and inadequate knowledge in managing the processes [22]. As a consequence, the weaknesses in the production process may lead to poor management, customer dissatisfaction and loosing market share [22]. Lean production is one of the methods generated by the idea of Toyota Production System in Japan that has been followed by most of the production companies nowadays. The main focus of lean production is to reduce waste and increase benefits [20] [24] [36]. The implementation of lean production can improve business performance, both in operation and financial [26].

A few benefits generated from lean production such as inventory reduction and help to increase customer satisfaction [31]. Lean production also contributes to continuous improvement, fully integrated management, comprehensive system of organizing and managing supply chain, headcount reduction, systematic tools and techniques to improve operations [38]. It was also claimed that lean production was a complex management system [13]. Lean production may also relate to asignificant change in a management system that could create resistance among the employees. Additionally, many found that the major failures in the implementation of lean production arise due to lack of intervention from leaders. A good leader is able to influence and motivate others, especially the employees. The lean implementation is difficult when there are no support and commitment from top management [19]. The top management role is important in managing and to be involved in the day to day activities in the company. They need to know what happens in the company and make solutions to solve any deficiency that occurs.

The complexity of lean production could lead to the failure in manufacturing companies. Leadership is an important influence on lean production in order for a company to have better performance. Many failures arose due to lack of communication and involvement of top management [19]. The pressure from a business environment that always changes could lead to the difficulties in implementing the lean program [29]. Thus, the objective of this research 
is to examine the influences of leadership styles in the relationship between the implementation of lean production and business performance among manufacturing companies. Lean production could be an interesting philosophy that could aid organization to make an improvement and reducing costs as well as waste. Additionally, this research studied the impact of the implementation of lean production towards business performance.

\subsection{CONCEPTUAL FRAMEWORK AND HYPOTHESES DEVELOPMENT}

\subsection{Lean Production}

Basically, common definition by most of the researcher regarding lean was that lean is waste elimination [4] [8] [27] [30]. When the waste was reduced, it would increase the value of the customer. Lean is to use less in everything. In another word, lean aimed to have more value with less work [5]. There are many tools of lean production. The wide choice of lean tools or practices for lean production or lean manufacturing can be confusing for those with limited knowledge of lean tools and their efficacy [2]. These tools and methods include value stream mapping, Kanban and pull, demand leveling, single-piece flow, 5S, Kaizen events, A3 reports, visual management and more [20]. Different industrial uses different tools, for example, in lean healthcare it is a better use Just in Time (JT) because, it can work with minimum resources which are necessary for health care. Meanwhile, in manufacturing, with several of literature support, the author has listed out the lean practices that commonly measured by the other researcher such as the cellular layouts, pull system, small lot production, and quick setup, and uniform production level, quality at the source, total productive maintenance and supplier networks.

\subsection{Lean Production and Business Performance}

Considerable prior research by [27] a study on the impact of lean practices on operations performance and business performance found that there is positive effect associated with lean manufacturing practices with operations performance and business performance. Lean manufacturing practices would lead to better operations performance in term of cost reduction, productivity, inventory minimization and quality. From a prior study by [25] between lean production and operational performance, there is also a positive relationship 
between them. Consequently, it generates towards operational excellence and better business performance.

According to [36] implementation of lean production in an airplane, do give impact to the performance of their cabin crew. They realized there is small changes as their project manager try to implement "lean cabin" slowly and does not want to give a big shock to their crews. After implementing it, the job is easier. For example, through Gemba walk, the impact is there is fewer places to look for cutlery, easier access to candy, less complexity in wine selection and lighter bottles and time saving [36]. This also can lead to a reduction of motion waste. Lean manufacturing could lead to better business performance because lean always have the right quality of the product, in right time and place [27]. One of the lean practices that can be used to improve the quality is through $5 \mathrm{~S}$, the quality of the sources and much more [27] [33]. The 5S methodology is well known in the manufacturing sector because it is a way to conduct business and lead to improvement of quality and productivity because, it involves a systematic process [33].

\subsection{Leadership Styles}

According to [1] found that leadership could improve the problem solving through work floor visit that allowed them to discover problems. In this study, the researcher examined whether leadership style as the moderating effect can influence the implementation of the lean production and business performance. This is distinguishing it from other study of lean production in manufacturing industries [32]. Managers claim themselves as a fast problem solver that can improve and achieve goal alignment [1]. When a problem was discovered, they can easily find a solution to make an improvement. As a leader, they must be trusted and capable of recognizing and resolving a problem. Leadership can influence the effectiveness and success of the lean production. For example, in the study by [13] different leadership behaviors affect the lean program. They summarized ideal leadership attributes into two main categories such as contributor leadership and inhibitor leadership. The result showed that contributor leadership such as communicative leadership has a moderate effect on the lean program [13]. There were three main leadership styles proposed by the Kurt Lewin in 1939 such as autocratic leadership, democratic leadership, and Laissez-faire leadership. He and his co-workers have identified those three styles. 
The three types of leadership styles that suggest by [23] could moderate the relationship between implementation of lean production and business performance. Despite all the different leadership styles, each of characteristic might influence the success of the lean production [9]. As mentioned by [13] autocratic leadership seems to be not suitable in lean context, but the result shows contradict. Similarly, for laissez-faire leadership, which has been said not preferable in the lean program [13]. However, other references said that laissez-faire leadership can be interpreted as a special character because of no all the managers willing to delegate authority and participate with their group members.

\subsubsection{Autocratic Leadership}

Leadership styles can affect the corporate culture and can maximize the profits of organizations. Some leaders are autocratic which receive and accept only minimal advice from their subordinates [13]. Autocratic leaders determine all the policy [23]. The leader also determined and set out the particular work task of companions of group members [23].

Autocratic leadership is the individual who has control over all decisions and contradicts with the democratic leadership. The leader also makes decisions in a dictatorial way [13]. In the lean context, the manager can solve problems with the help of their group members without acting like a bossy and ruler [13]. According to [13] autocratic leadership is unsuitable for lean management but however, the result shows contradict. This means that the autocratic leadership also can contribute to the successful implementation of lean production.

According to [37] they found that autocratic leadership style could create dilemmas within the public. In order to provide the common good, leaders will do whatever they feel is necessary. They decided by their own without any discussion and they decided which group members should contributes without asking team members for input [37]. As consequences, team members generally unwilling to assign an autocratic leader to deal with conflicts. However, an autocratic leadership could be effective in a mass production environment. This kind of attributes may be more useful in short term period rather than long term [13].

\subsubsection{Democratic Leadership}

Meanwhile, democratic leadership encouraged and assisted the group members on the issue of policies. The group members were free to work in their own and free to work with whoever 
they choose [23]. In the point of view of [23] democratic leadership is a person who could not tell the group members exactly what they should do because if the leaders do so, it will change to the autocratic leadership.

Democratic leadership is where the leaders allow for participation by the employees to generate more creativity and ideas. This style creates an effective and most appreciation by followers. However, democratic process is complex and it requires an effort from leaders and group members itself to play their role. The democratic attributes also can actually prevent from worst extremes of social conflicts [6]. Although democracy has been defined, there is no clear and well-developed definition of the term [12].

The advantage that can be gained through democratic style is that the group members can act as leaders, even though they have no formal authority [12]. This is to allow for more participation and create an open discussion within the leader and group members. Democratic leadership concerned with giving others the authority to lead [16]. It is a positive characteristic of leadership, especially in lean manufacturing because as mentioned, it opens for more discussion and problem-solving [12]. It could result in better desirable outcomes and independent followers are produced.

\subsubsection{Laissez-faire Leadership}

Laissez-faire leaders have very little involvement with group members. They often give complete freedom for group on their decision. It also known as non-participation by leaders [23]. The leader keeps hand offs or avoid for intervention within group members [3]. It is said that this style is zero leadership style because it is a lack of presence and not meeting any legitimate expectations of employees [35]. In lean context, it could be that this style could be a root cause of conflict in the workplace. This approach lacks motivation and did not help for active leadership. Thus, it can increase the level of role conflict and role ambiguity [35]. In fact, [35] found that laissez faire leadership has a correlation with bullying, workplace stressors, and psychological distress.

Furthermore, the leader tends to let their subordinates work problems out on their own. Leaders should have intervention within their group members, but in contrast, laissez faire leader offers freedom within their subordinates and attempts to avoid interference in decision making [7]. They also allowed for personal decision by their subordinates and they are free to 
do their work in their own way. They might seem lazy and in fact, they also avoid for making feedback. They believe by providing sufficient material and time to their subordinate, at least, more than enough [7]. However, in term of motivation, actually this leader can give a positive relationship with intrinsic and extrinsic motivation. This is maybe because of the freedom that was given to their subordinates. They might feel more motivated to do their work in their own way and more enjoy doing work because of no pressure, unlike autocratic leadership.

\subsection{Contingency Theory}

It was found that contingency theory is the best suit for the lean program. It is also known as "it all depends on" theory. The contingency theory of management accounting concluded that there is no specific applicable system within the management control [28]. The choice of the appropriate control techniques is crucial and depending on the situations that the company may face. Contingency theory, providing an insight into the role and functioning of management accounting [15]. Lean manufacturing can be problematic and can be beneficial towards the company, depending on different factors.

Contingency theory is needed to fit with all the unexpected circumstances and since the lean is a complex system, it is the best suit with this theory [13]. There is no best way to structure the company and they must have a quick response to their structure to fit their environmental contingencies [11]. Contingency theory is also represented in leadership studies [13]. There are various types of leadership styles that can influence the successfulness of lean production and business performance.

The relationship between contingency theory with leadership styles is there is no correct style imposed to the leader [21]. The different circumstances can direct the leader to act in different ways. For example, some company prefers autocratic leadership in order to have more quick decision by making the leader make all the decision [21]. Meanwhile, some consider having democratic leadership styles to create more creative and participation from employees. This theory also explained that the best leadership styles are depending on the different characteristics of team members [21].

\subsection{Conceptual Framework}

Figure 1 showed the conceptual framework for this study. The framework showed the relationship between the lean production (independent variable) and business performance 
(dependent variable). Additionally, the relationship is moderated by leadership styles (moderator variable). This research is to examine the relationship between lean production and business performance and the influence of leadership styles between lean implementation and business performance.

There was much previous research explained about the relationship between lean production and business performance such as [18] [27] and much more. [18] study on the impact of lean production on the financial performance of manufacturing companies. They found there is a significant and positive effect of lean practices on financial performance. It could increase the profitability of the organization especially in their return on sales [18]. Based on the study by Nawanir et al. [27] they also found a relationship between lean production and business performance. Lean manufacturing practices have a correlation between operations performance and also financial performance. The result shows an enhancement in productivity, delivery, quality, and reduction on cost and inventory minimization [27]. Meanwhile, a prior study by Losonci and Demeter (2013) examine relationship between lean production and operational performance. The result showed a positive relationship between lean production and operational performance. Consequently, it generates towards operational excellence and better business performance [25]. 


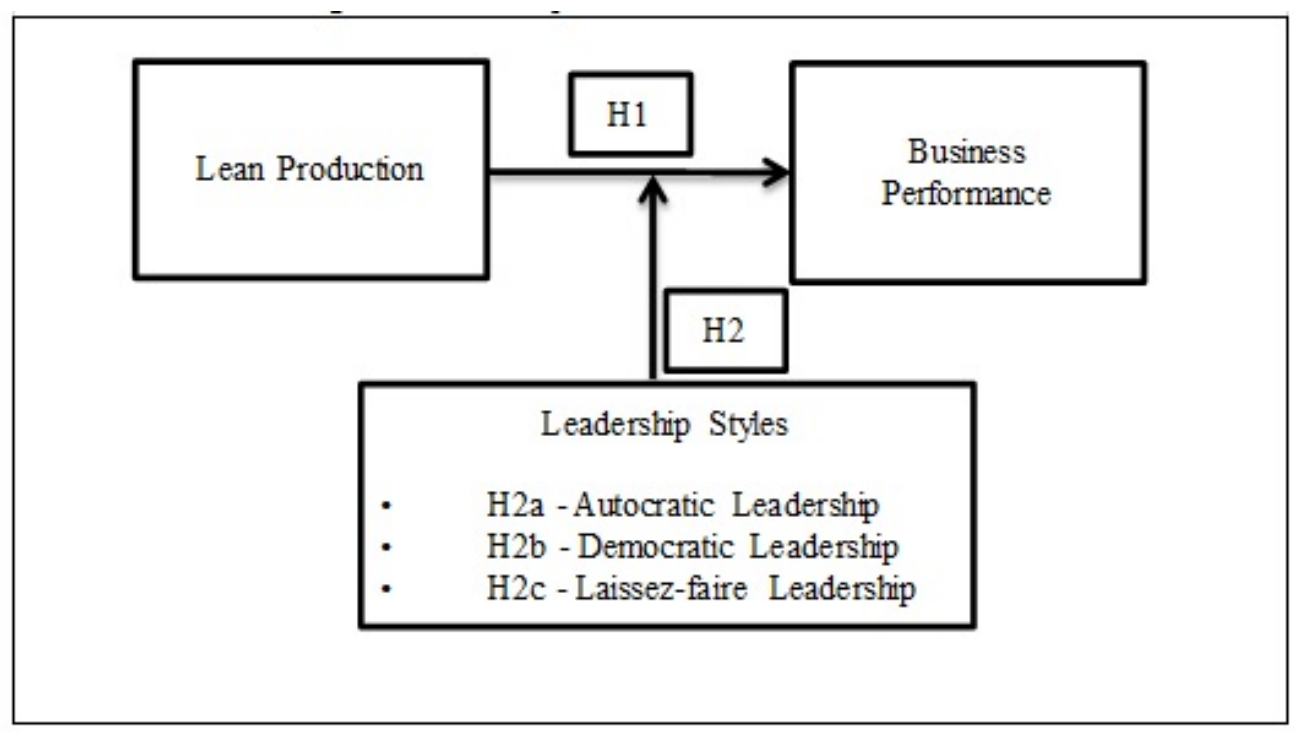

Fig.1. Conceptual framework of the research

There are not many studies on the moderation effects of leadership styles between lean implementation and business performance. Many reason of the failure in lean implementation due to lack of support and commitment from top management. Lean production is a complex system and it requires involvement from a leader to make significant changes [13].

Therefore, this research is to examine on the influences of the leadership styles between the implementation of lean production and business performance. Leadership is an important influence on lean production in order to have better performance.

\subsection{Hypotheses Development}

There are two main hypotheses; The first hypothesis is to examine whether there is a positive relationship between lean production and business performance. The second hypothesis is to examine the moderator effect of each leadership styles between the implementation of lean production and business performance.

H1: Lean production implementation has positive relationship with business performance Based on the past literature, theoretically lean production has positive correlation with business performance [18] [25] [27]. According to [18] the adoption and implementation of lean production into their organization has resulted in better financial performance. Lean productions led to reduction of operational cost and other associated costs [18]. Lean practices also associated with the operating performance [27]. The higher lean manufacturing was 
practiced, would result in better operating performance in term of cost reduction, productivity, delivery, inventory minimization and quality.

H2a: Autocratic leadership style moderates the relationship between the implementation of lean production and business performance.

According to [13] autocratic leadership is unsuitable for lean management but however according to the result it is showing contradict answer. This is meaning that the autocratic leadership also can contribute to the successful implementation of lean production. It is effective to use leadership style to make a quick decision on the problem faced. An autocratic leadership could be effective in a mass production environment [13]. Lean production is complex management system because it requires significant changes throughout the organization [13]. Leadership behavior can influence the applicability and success of the practices within the company. The success of the lean program will depend on how leadership influences the people inside the company. Somehow, workers are reluctant to make significant changes without enforcement from the manager. Therefore, in this case, autocratic leadership a style is needed to make a fast response and to make sure all employees could follow what organization has planned.

H2b: Democratic leadership style moderates the relationship between the implementation of lean production and business performance.

Democratic leadership concerned with giving others the authority to lead [16]. It is a positive characteristic of leadership especially in lean manufacturing because as mention, it opens for more discussion and problem-solving [12]. It could result in better desirable outcomes and independent followers are produced. Even though the authority is given to the subordinates, the final decision will be imposed to the manager or leader. It is believed that this leader also can contribute good values to the society by preventing social conflict [6]. The humanistic concept is also similar to this approach as it takes others people into consideration as well give freedom and innovation rather being dominated. According to [24] one of the failures of lean implementation was lack of communication and commitment from top management [24]. Hence, democratic leadership could promote more medium of communication.

H2c: Laissez-faire leadership style moderates the relationship between the implementation of lean production and business performance. 
Laissez faire type is where the leader keeps hand offs or avoid for intervention within group member [3]. It is said that this style is zero leadership style because it is a lack of presence and not meeting any legitimate expectations of employees [35]. In lean context, it could be that this style could be a root cause of conflict in the workplace. However, this leader could give a positive relationship with intrinsic and extrinsic motivation. They believe by allowing employees more freedom, can increase their leadership success. Unlike an autocratic leadership this leadership encouraged employees to create creative culture and more motivated and enjoy the work [7].

\section{RESEARCH METHODOLOGY}

The unit analysis in this study is organization in manufacturing industries in Malaysia. This study uses quantitative approach and data collection is through questionnaires. This is to measure the non-financial performance of the business. A survey conducted and questionnaires were distributed to manufacturing companies all over Malaysia.

The target respondents are production manager, engineer, supervisor, director or anyone who knows about production. The questionnaire was mailed and some were distributed by hand. They required returning the survey immediately after they received the email. As a result, this study able to obtained 44 percent of response rate which consists of 44 respondents. The measurement of all three variables was perceptual with a five-point Likert scale: scale range from one (Strongly Disagree) to five (Strongly Agree).

\section{DISCUSSION OF RESULTS}

\subsection{Respondent profile}

A total of 44 useable responses were received. The information was gathered to obtain overall background information of respondents as well as the respondents companies. The majority of respondents held the position of engineer and supervisor at 15 and 13 respondents respectively. Moreover, majority of the companies among the manufacturing industries have been operating more than 10 years with 20 respondents. This indicates that most of the respondents are having a long period of operations. The majority in industry classification is "others" which comes from healthcare, ceramic, supplier and logistic company, automotive, 
compact disc (CD), LED lighting and others manufacturing. The second highest is coming from electrical and electronic industry with 12 respondents followed by food processing industry with 8 respondents, engineering supporting 3 respondents, machinery and equipment 2 respondents, petrochemical and polymer and textiles and apparel with 1 respondent for each industry.

Many of companies have less than RM 5 million of annual sales revenue. Only a few of companies have annual sales range from RM 51 million to RM 100 million and more than RM 100 million. This indicated that the companies might be small and medium size companies. A reliability test was conducted in this research based on 44 (44\%) responses received. Table 1 showed the Cronbach's Alpha for each variable in this study. Based on the result below, the Cronbach's Alpha for lean production is 0.944 which is excellent [14]. Similar to business performance, the Cronbach's Alpha shows 0.938 which is excellent. For the autocratic leadership styles, the Cronbach's Alpha shows 0.730. According to rules of thumb of Cronbach's Alpha, the value is good and acceptable [14].

Similarly, the Cronbach's Alpha for democratic leadership is 0.783 which is good and acceptable. Last but not least, the reliability for Laissez-faire leadership is 0.816 indicate good result. Therefore, it can be concluded that all of the variables are reliable and indicates that the internal consistency for reliability for all items is good.

Table 1. Reliability statistics

\begin{tabular}{lcc}
\hline \multicolumn{1}{c}{ Variables } & Cronbach's Alpha & N of items \\
\hline Lean Production & 0.944 & 47 \\
Business Performance & 0.938 & 21 \\
Autocratic Leadership & 0.730 & 6 \\
Democratic Leadership & 0.783 & 6 \\
Laissez-faire Leadership & 0.816 & 6
\end{tabular}


Table 2. Normality test

\begin{tabular}{ccccc}
\hline Variables & \multicolumn{2}{c}{ Skewness } & \multicolumn{2}{c}{ Kurtosis } \\
\hline LP & 0.032 & 0.357 & 0.376 & 0.702 \\
BP & 0.435 & 0.357 & -0.159 & 0.702 \\
A_LS & 0.294 & 0.357 & -0.703 & 0.702 \\
D_LS & 0.076 & 0.357 & -0.965 & 0.702 \\
L_LS & -0.099 & 0.357 & -0.461 & 0.702 \\
\hline
\end{tabular}

\subsection{Normality Test}

Based on table 2, the skewness and kurtosis for three variables are normally distributed. All variables meet the rule of thumb where LP (0.32), BP (0.435), A_LS (0.294), D_LS (0.076) and L_LS (-0.099) for skewness and LP (0.376), BP (-0.159) and A_LS (-0.703), D_LS (-0.965), and L_LS (-0.461) for kurtosis. Thus, it can be concluded that the normality test does not violate and the data is normally distributed.

\subsection{Descriptive Analysis}

Based on table 3, the total mean score of lean production (LP) is 3.93, indicates that most of manufacturing companies in Malaysia did implement lean production. Even though the range is moderate, but we can conclude that most of manufacturing companies aware on the importance of lean production. Meanwhile, the result for total mean score of business performance $(\mathrm{BP})$ is 3.88 , indicates that lean production has affected their business performance in term of quality, inventory minimization, delivery, productivity and cost reduction.

Table 3. Descriptive analysis

\begin{tabular}{cccc}
\hline Variables & Min & Max & Mean \\
LP & 2.81 & 5 & 3.93 \\
BP & 2.71 & 5 & 3.88 \\
\hline
\end{tabular}


The measurement of leadership styles as moderator is different from other variables. Based on the table 4 portrayed the descriptive statistic of overall leadership styles. The table shows the mean for each style of leadership. The highest total mean for 44 respondents believes democratic leadership styles is more preferable with mean score 4.05. The mean score interprets that most of the respondents are agree to act as a democratic leader. The second highest mean is autocratic leadership styles with a mean of 3.64. Autocratic is needed in lean manufacturing to make quick decision making in mass production.

Table 4. Descriptive statistic of leadership Styles $(n=44)$

\begin{tabular}{lccccc}
\hline & N & Mini & Max & Mean & $\begin{array}{c}\text { Std. } \\
\text { Deviation }\end{array}$ \\
\hline Autocratic & 44 & 2.67 & 5 & 3.64 & 0.648 \\
Democratic & 44 & 3 & 5 & 4.05 & 0.595 \\
Laissez-faire & 44 & 1.67 & 5 & 3.4 & 0.821 \\
\hline
\end{tabular}

The least mean score with 3.40 is laissez-faire leadership styles. This leadership offers no participation and intervention within group members. This style gains the least number of the score within the minimum column with 1.67. This indicates that most of the respondents strongly disagree that laissez faire leadership is suitable in lean context. It is said that this style is zero leadership style because it is a lack of presence and not meeting any legitimate expectations of employees [35]. 
Table 5. Descriptive statistic of leadership styles $(n=44)$

\begin{tabular}{lccc}
\hline & Freq & Percent & $\begin{array}{c}\text { Cumulative } \\
\text { Percent }\end{array}$ \\
\hline Autocratic & 7 & 15.9 & 15.9 \\
Democratic & 34 & 77.3 & 93.2 \\
Laissez-faire & 3 & 6.8 & 100 \\
Total & 44 & 100 & 100 \\
\hline
\end{tabular}

Table 5 represents the numbers of respondents for each style. This result is gathering based on the high mean score. Based on the result, 77.3 percent of respondents with a total of 34 people represent democratic leadership styles. This result in line with the previous total means score where democratic styles have a high mean score. This type of leader allows for participation by their employees to generate more creativity and ideas. This style also creates an effective and most appreciate by followers [3]. The Democratic attributes also can actually prevent from worst extremes of social conflicts [6].

The second highest number of respondents is autocratic leadership with 15.9 percent. However, the total number of people is still smallest compared to democratic leadership. There are few people agree to act as autocratic leadership in lean manufacturing because of autocratic leadership is where a person act likes a ruler and boss. This leadership can help in making a quick correction and decision in the production process. Meanwhile, laissez-faire leadership styles have least number of respondents with 6.80 percent. They believe that as a leader you need to guide your subordinate and allow for participation.

\subsection{Correlation Analysis}

There was a high correlation between the independent variable and dependent variable. Based on the rule of thumbs the range of correlation between 0.70 to 0.89 is represented high correlation [17]. Table 6 portrayed that lean production has a positive high relationship with business performance with $\mathrm{r}=0.719$. This result supports the objective in this study which to examine the relationship between the implementation of lean production and business performance. 
Table 6. Correlation matrix between variables

\begin{tabular}{|c|c|c|}
\hline Variables & $\begin{array}{c}\text { Lean } \\
\text { Production }\end{array}$ & $\begin{array}{c}\text { Business } \\
\text { Performance }\end{array}$ \\
\hline $\begin{array}{c}\text { Lean } \\
\text { production }\end{array}$ & 1 & $.719 * *$ \\
\hline $\begin{array}{c}\text { Business } \\
\text { Performance }\end{array}$ & $.719 * *$ & 1 \\
\hline
\end{tabular}

\subsection{Test of Hypotheses}

\subsubsection{Simple Regression Analysis}

Table 7. Simple regression analysis result

\begin{tabular}{lccc}
\hline \multicolumn{3}{c}{ Business Performance } \\
& $\begin{array}{c}\text { Standardized } \\
\text { Beta }\end{array}$ & $t$-value & $\begin{array}{c}\text { Sig. } \\
\text { value }\end{array}$ \\
\hline Lean & 0.719 & 6.709 & 0.00 \\
Production & & 0.517 & \\
$\mathrm{R}^{2}$ & & & \\
Adjusted & & 0.506 & \\
$\mathrm{R}^{2}$ & & & \\
\hline
\end{tabular}

Significant at 0.00 level* $^{*}$

Refer to table $7, \mathrm{R}^{2}$ was referring to explain how much variance in the business performance is explained by lean production. It also to measure how close the data with a regression line. The $\mathrm{R}^{2}$ is 0.517 with adjusted $\mathrm{R}^{2}$ of 0.506 indicate that the linear regression explains $51.7 \%$ of the variance in the data. In simple words, $51.6 \%$ of the variation in business performance is explained by variation in lean production. From the above table, the standardized beta shows the level of the contribution by lean production to explain business performance. The result shows lean production has a strong contribution to explain business performance with 0.719 standardized betas. The significant value explained whether the variable making a significant contribution to the equation or not. Based on the result the significant value is less than 0.05 indicate that the lean production gives a significant contribution to the business performance. 
Thus, it can be said that lean production has a positive and significant relationship with business performance $(\mathrm{Beta}=0.719, \mathrm{p}<0.05)$. Overall, hypothesis 1 is supported.

\subsubsection{Hierarchical Regression Analysis}

The hierarchical regression analysis is used to test the moderation effect. Based on the Table 8 , the significant value for the interaction term between lean production and autocratic leadership towards business performance is $p=0.644$. This significant value is exceeding 0.05. This can be concluded that autocratic leadership did not make moderation effect between the relationship of lean production and business performance. Thus, H2a is not supported. Democratic leadership style is very preferable among all the styles. The significant value is 0.037 where $\mathrm{p}<0.05$. This indicated that democratic leadership style has a moderate effect on the relationship of lean production and business performance. Thus, H2b is supported. Based on the result for laissez-faire leadership, the significant value is $p=0.307$ with $\mathrm{R}^{2}$ change 0.012 indicate that there is no moderation effect between the relationship of lean production and business performance since the $\mathrm{p}$ value of interaction items is not significant $(\mathrm{p}>0.05)$. There is also small $(1.5 \%)$ increasing in the variance of business performance explained by the interaction items. Thus, H2c is not supported.

Table 8. Hierarchical regression analysis

\begin{tabular}{lccc}
\hline Unstandardized & & \\
Interaction Items & $\begin{array}{c}\text { Coefficients } \\
\text { (Beta) }\end{array}$ & R2 & Sig. \\
& -0.014 & 0.003 & 0.644 \\
\hline LP_x_Autocratic & 0.07 & 0.049 & 0.037 \\
LP_x_Democratic & 0.22 & 0.012 & 0.307 \\
\hline LP_x_Laissez.faire & & & \\
\hline
\end{tabular}

\section{FINDINGS AND CONCLUSIONS}

\subsection{Findings}

As shown in the data analyses, lean production has been implemented by a number of Malaysian manufacturing companies. The result is comparable with previous studies conducted in others countries. Based on this study, manufacturing companies in Malaysia 
were moderately committed to implement the lean production. Many researchers have found that there is a positive correlation between lean implementation and business performance [18] [25] [27]. Based on the result proved that lean production has a positive and significant relationship with business performance $(\operatorname{Beta}=0.719, \mathrm{p}<0.05)$. This result supports the evidence from previous study. Lean production gives positive relationship in term of quality, inventory minimization, delivery, productivity and cost reduction.

This main study was to examine the influences of leadership styles towards implementation of lean production and business performance. There are three leadership styles were concerned, such as autocratic, democratic, and laissez-faire leadership style. Based on the result, only one leadership style has moderation effect between the implementation of lean production and business performance. The result showed hypothesis H2a is not supported. According to [13] autocratic leadership is unsuitable for lean management. Many study found that autocratic leadership style can create dilemmas within the public. In order to provide the common good, leaders will do whatever they feel is necessary (Vugt et al., 2004). They will decide by their own without any discussion and they will decide which group members should contribute how much without asking team members for input [37]. As consequences, team members generally unwilling to assign an autocratic leader to deal with conflicts.

Meanwhile, democratic leadership style showed significant moderating effect between the implementation of lean production and business performance. The result showed hypothesis $\mathrm{H} 2 \mathrm{~b}$ is supported. The leaders allow for participation by the employees to generate more creativity and ideas. It's also promote more medium of communication. It is a positive characteristic of leadership especially in lean manufacturing because as mention, it opens for more discussion and problem-solving [12]. Last but not least, the laissez-faire leadership showed that it did not have moderating effect in the relationship between implementation of lean production and business performance. The result showed hypothesis $\mathrm{H} 2 \mathrm{c}$ is not supported. Based on the result, the significant value is $p=0.307$ indicate that there is no moderation effect between the relationship of lean production and business performance. The leader tends to let their subordinates work problems out on their own. Leaders and employees need to work together to achieve the desired outcomes. It requires the participation of both, 
leaders and employees [10]. The success of the lean program will depend on how the leadership can influence the people inside the company

\subsection{LIMITATION AND FUTURE RESEARCH}

This study is not without limitation. As in all survey, the respondents had sufficient knowledge to answer the questionnaire. The limitation of this study was the low response rate for the distribution of questionnaires. This study provides very long questions that make many of respondents answer the question half way. The main target respondent was production manager, and many of them were busy with their schedule and had limited time to answer the survey. Moreover, some companies had their factory outside Malaysia and some of them refused to answer the survey. Further research should continue to investigate lean on the other industry other than manufacturing. There is also another past research on, lean in healthcare, lean leadership and much more. The future research also can examine the impact on the financial performance rather than non-financial. Other types of leadership styles also can be further investigated such as transformational, inspirational and much more.

\section{REFERENCES}

[1] Aij K H, Visse M, and Widdershoven G A M. Lean leadership: An ethnographic study. Leadership in Health Services, 2015, 28(2):119-134

[2] Alaskari O, Ahmad M M, and Cuenca R P. Development of a methodology to assist manufacturing SMEs in the selection of appropriate lean tools. International Journal of Lean Six Sigma, 2016, 7(1):62-84.

[3] Allport G W. Resolving social conflicts: Selected papers on group dynamics. In G. W. Lewin Ed.), New York: Harper \& Row, John Weatherhill. Inc. (1948)

[4] Alves A C, Carvalho J D, and Sousa R M. Lean production as promoter of thinkers to achieve companies' agility. The Learning Organization, 2012, 19(3):219-237

[5] Anvari A, Ismail Y, and Hojjati S M H. A study on total quality management and lean manufacturing: Through lean thinking approach. World Applied Sciences Journal, 2011, 12(9):1585-1596

[6] Burnes B. Kurt Lewin and the planned approach to change: A re-appraisal. Journal of 
Management Studies, 2004, 41(6):977-1002

[7] Chaudhry A Q, Javed H. Impact of transactional and laissez faire leadership style on motivation. Journal of Business and Social Science, 2012, 3(7):258-264

[8] Dahlgaard J J, Pettersen J, Park S M D. Quality and lean health care: A system for assessing and improving the health of healthcare organisations. Journal of Total Quality Management \& Business Excellence, 2011, 22(6):673-689

[9] Dombrowski U, Mielke T. Lean leadership: Fundamental principles and their application. Journal of Procedia CIRP, 2013, 7, 569-574.

[10] Dombrowski U, Mielke T. Lean leadership: 15 rules for a sustainable lean implementation. Journal of Procedia CIRP, 2014, 17, 565-570

[11] Fullerton R R, Kennedy F A, Widener S K. Lean manufacturing and firm performance: The incremental contribution of lean management accounting practices. Journal of Operations Management, 2014, 32(7-8):414-428

[12] Gastil J. A definition and illustration of democratic leadership. Journal of Human Relations, 1994, 47(8):953-971

[13] Gelei A, Losonci D, and Matyusz Z. Lean production and leadership attributes: The case of Hungarian production managers. Journal of Manufacturing Technology Management, 2015, 26(4):477-500

[14] George D, Mallery P. SPSS for Windows step by step: A simple guide and reference: 11.0 update $\left(4^{\text {th }}\right.$ Ed), Boston: Allyn \& Bacon, 2003, p.231.

[15] Granlund M, Lukka K. Investigating highly established research paradigms: Reviving contextuality in contingency theory based management accounting research. Journal of Critical Perspectives on Accounting, 2017, 45, 63-80

[16] Harris A, Chapman C. Democratic leadership for school improvement in challenging contexts. International Electronic Journal for Leadership in Learning, 2002, 6(9):1-9

[17] Hinkle D E, Wiersma W, and Jurs S G. Applied statistics for the behavioral sciences. Boston, Mass: Houghton Mifflin, 2003

[18] Hofer C, Eroglu C, and Hofer A R. The effect of lean production on financial performance: The mediating role of inventory leanness. International Journal of Production Economics, 2012, 138(2):42-253 
[19] Holm M. Leadership for lean operations. Journal of Leadership Research, 2010, 1-7

[20] Kadarova J, Demecko M. New approaches in lean management. Procedia Economics and Finance, 2016, 39, 11-16

[21] Kibbe M R. Leadership theories and styles. In M. R. Kibbe \& H. Chen (Eds.), Leadership in surgery: Success in academic surgery. Cham: Springer International Publishing, 2015, pp 49-57.

[22] Kumar B R R, Kumat S M, and Agarwal A. An experimental investigation of lean managemnt in aviation: Avoiding unforced errors for better supply chain. Journal of Manufacturing Technology Management, 2014, 26(2):231-260

[23] Lewin K, Lippitt R, White R K. Patterns of aggressive behavior in experimentally created social climates. Journal of Social Psychology, 1939, 10:271-301

[24] Ljungblom M. Ethics and lean management - a paradox? International Journal of Quality and Service Sciences, 2014, 6(2/3):191-202

[25] Losonci D, Demeter K. Lean production and business performance: International empirical results. International Business Journal, 2013), 23(3):218-233

[26] Narayanamurthy G, Gurumurthy A A. Leanness assessment: A literature review. International Journal of Operations \& Production Management, 2016, 36(10):1115-1160

[27] Nawanir G, Teong L K, Othman S N. Impact of lean practices on operations performance and business performance. Journal of Manufacturing Technology Management, 2013, 24 (7):1019-1050

[28] Otley D. Performance management: A framework for management control systems research. Journal of Management Accounting Research, 1999, 10(4):363-382

[29] Pamfilie R, Petcu A J, Draghici M. The importance of leadership in driving a strategic lean six sigma management. Journal of Social and Behavioral Sciences, 2012, 58, 187-196 [30] Pettersen J. Defining lean production: Some conceptual and practical issues. The TQM Journal of Business Theory and Practice, 2009, 21(2):127-142

[31] Rose A N M, Rashid M F F A, Mohamed N M Z N, and Ahmad H. Similarities of lean manufacturing approaches implementation in towards the success: Case study in the automotive component industry. The $9^{\text {th }}$ International Unimas Stem Engineering Conference, 2017,87 
[32] Rotemberg J J, Saloner G. Leadership style and incentives. Journal of Management Science, 1993, 39(11):1299-1318

[33] Sánchez P M, Rodriguez C M, Maruyama U, and Salazar F. Impact of 5S on quality, productivity and organizational climate: Two analysis cases. Proceedings of the International Conference on Operations Excellence and Service Engineering, 2015, 748-755

[34] Sim K L, Rogers J W. Implementing lean production systems: Barriers to change. Management Research News, 2008, 32(1):37-49

[35] Skogstad A, Einarsen S, Torsheim T, Aasland M S, and Hetland H. The destructiveness of laissez-faire leadership behavior. J Occup Health Psychol, 2007, 12(1):80-92

[36] Thorhallsdottir T V. Implementation of lean management in an airline cabin, a world first execution? Journal of Social and Behavioral Sciences, 2016, 226, 326-334

[37] Vugt M V, Jepson S F, Hart C M, and Cremer D D. Autocratic leadership in social dilemmas: A threat to group stability. Journal of Experimental Social Psychology, 2004, 40(1): $1-13$

[38] Zakaria N H, Mohamed N M Z N, Rahid M F F A, and Rose A N M. Lean manufacturing implementation in reducing waste for electronic assembly line. The $2^{\text {nd }}$ International Conference on Automative Innovation and Green Vehicle, 2017, 90

\section{How to cite this article:}

Zarinah A R, Nur Farhana A M, and Nadiah A H. Lean production and business performance: influences of leadership styles Article. J. Fundam. Appl. Sci., 2017, 9(5S), 1030-1051. 